\title{
La zona de integración fronteriza colombo - venezolana. La integración sostenible y el funcionalismo actual, un análisis descriptivo.
}

\author{
ÁNGELA JULIETA MORA RAMÍREZ \\ amoraram@poligran.edu.co
}

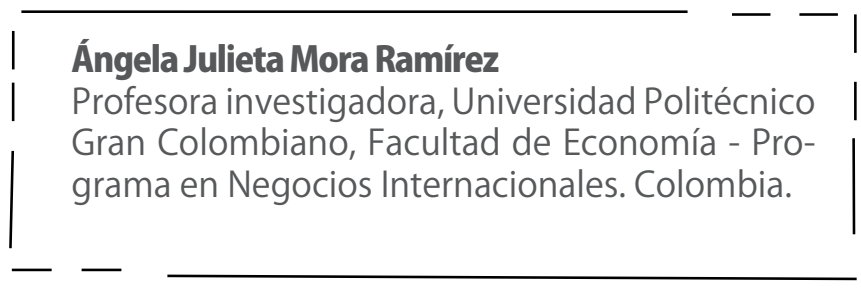

\section{RESUMEN}

El objetivo de esta investigación es realizar un estudio, sobre el concepto de integración sostenible, y desarrollar un análisis descriptivo de la Comunidad Andina, y la negociación comercial fronteriza de Colombia y Venezuela, zona Táchira( Venezuela) Norte de Santander (Colombia), desde la teoría funcionalista actual, y la integración sostenible.

Hoy es necesario establecer criterios conjuntos de cooperación, y analizar, a partir de los conceptos, la integración total y sostenida, su importancia en el comercio y sus implicaciones actuales, ya sea por acuerdos binacionales, o, por acuerdos alternativos de cooperación que se fundan en estrategias supranacionales, que solidifican el proceso sin permearlo con situaciones coyunturales, y afectan el proceso mismo de negociación. También es necesario ver lo global desde lo local o regional; desde las fronteras, las cuales desarrollan un flujo de transacciones de altos volúmenes de productos y servicios; por tanto, se propone incrementar los estudios de lo local para lograr adaptarse a lo interdependiente.
La profesora Ángela Julieta Mora es economista, especialista en integración con más de diez años de experiencia y múltiples publicaciones sobre estos temas en revistas colombianas e internacionales, profesora de gran trayectoria docente especialmente en temas de investigación.

\section{PALABRAS CLAVE}

Integración, internacional, zonas de integración fronteriza.

\section{ABSTRACT}

The objective of this research is to conduct a study on the concept of sustainable integration, and develop a descriptive analysis of the Andean Community, and commercial negotiation border of Colombia and Venezuela, from the current functionalist theory, and sustainable integration. Showed the need to establish criteria sets, making cooperation homogeneous, and projecting from the same concepts, the total integration and sustained its importance and its trade implications today. An alternative is to see what overall from the local, from the regional, from the borders, which developed a flow of high volumes of transactions of goods and services, thus aims to increase the local studies to achieve adapt to the interdependent.

\section{KEY WORDS}

Integration, international, frontier integration zones 


\section{INTRODUCCIÓN}

Esta investigación se desarrolla con el fin de establecer análisis alternativos, acerca del proceso de integración sostenible en la CAN, entendido este como la formación de una negociación profunda y equilibrada entre los Estados, que sugiere un reto supranacional y comunitario. El objetivo central de este análisis descriptivo es estudiar la sostenibilidad de la integración, en especial, desde lo local a lo regional de lo pequeño a lo grande, de lo micro a lo macro.

Se realizará una descripción de los conceptos básicos de la integración sostenible y de los pasos de la integración como concepto y como estrategia de desarrollo de los Estados nacionales, desde la cooperación regional, y la teoría de la integración: el Funcionalismo, cuyo principal exponente fue D. Mitrany ${ }^{1}$, quien escribió durante el periodo de entreguerras y posguerra, inspirado en el creciente auge de las organizaciones internacionales desde fines del siglo XIX, así como en las ideas del socialismo británico.

"El punto de partida de su pensamiento fue la idea de la incapacidad del Estado de satisfacer determinadas necesidades básicas, como la seguridad y el bienestar. Esta incapacidad se debía a la creciente presencia de tareas técnicas en el ámbito interno, y fundamentalmente internacional. La solución a estos problemas vendría con la cooperación e integración internacional, que llevaría a la creación de una red de organismos internacionales, que se encargarían de gestionar determinadas tareas. Este modelo de integración tenía dos particularidades, por un lado, no era necesaria la participación de los Estados; esta se realizaría entre técnicos y no entre elites políticas. A su vez la percepción de que las necesidades básicas son satisfechas de mejor manera por organismos supranacionales, produciría una lenta transferencia de lealtades desde el Estado nación hacia las diferentes organizaciones internacionales. Lo que por otro lado disminuiría la posibilidad de conflictos internacionales violentos" ${ }^{2}$.

En la segunda parte me centraré en el análisis de la CAN y en especial en lo referente a zonas de integración fronteriza, su importancia como factor de la integración sostenible para países como los nuestros, y el análisis del caso Colombia-Venezuela desde la fronte$\mathrm{ra}$, que es un enfoque binacional sobresaliente en los procesos de negociación actual.

\section{METODOLOGÍA.}

Para establecer este estudio, se hace necesaria la implementación de un análisis documental, qué posibilite la configuración de una herramienta de comparación cuantitativa y cualitativa.

En el escenario de lo cuantitativo, se busca la configuración de un resumen de flujo comercial en el que se evidencia el volumen del comercio, dentro del marco de la ZIF. Asimismo, se hace necesario aplicar una herramienta de análisis que desde la normatividad, la teoría funcionalista, y la configuración supranacional, se traduzca en dos escenarios que se conviertan en la arena de discusión de la agenda comercial. El primer escenario es el que hace referencia directa a la cotidianidad de la negociación fronteriza, en cuanto a la actividad económica que gestiona y desarrolla el Estado para dar respuestas a sus políticas en integración y negociación; y el segundo escenario, corresponde a una configuración de carácter normativo, que busca implementar en la subregión de la CAN, políticas económicas globales que marcan los derroteros de las relaciones comerciales entre los Estados-nación, desde lo local a lo regional, como alternativa de integración sostenible y funcional de cooperación.

La comprobación de la investigación se establece con la recopilación documental, la indagación, y el estudio sobre las teorías de cooperación (funcionalista), y la búsqueda de la integración sostenible por parte de la CAN, desde las zonas de integración fronteriza (ZIF), valiéndome no solo de la teoría, sino estableciendo una opción de estudio enfocada a lo local y lo regional, hacia lo global y lo mundial, determinada por la actual y moderna interdependencia. Igualmente es importante agregar que este análisis verifica documentación y obtiene de la información primaria, datos que permiten analizar, y establecer puntos de vista en un enfoque, que se estructura como una investigación real, que permite visualizar perspectivas, y que desarrolla una investigación descriptiva estructurada, herramienta del lector, en el análisis conceptual.

1 La Unión supranacional se ha formado como una forma de organización específica para el paso de un Estado nacional a un Estado federal de un espacio cultural (Estado-civilización [Kulturkreis-Staat]) que unirá en su seno diferentes naciones y culturas nacionales correspondientes todas a una misma civilización (occidental, oriental-islámica, etc.). En el marco de un proceso de integración, la unión supranacional está objetivamente constituida para conducir a los Estados nacionales que están continuamente sobrecargados por las exigencias de la globalización y de la georegionalización, a un "Estado-fusión” federal [Vereinigungs-Bundesstaat], previsiblemente un Estado-civilización y no un nuevo Estado nacional. (Tomado de: Capítulo 2: Una nueva forma de organización: la Unión supranacional de Dr. Thomas Scmitz en http://lehrstuhl. jura.uni-goettingen.de/tschmitz/SupranUnion/Resumen-2.htm).

2 Bisceglia, Nicolás Emiliano. Director de Asuntos Políticos del Centro de Estudios Políticos para América del Sur. "Los procesos de integración y cooperación: hacia un modelo posible". <http://www.unionsudamericana.net/castellano/notas/opi_003.html: Consultado 13 de marzo de 2008> 
Para este estudio limitaré mi análisis a la ZIF Norte de Santander( Colombia) y Táchira (Venezuela), y su mayor flujo comercial, con el fin de establecer un eje de estudio, y una mayor indagación de datos y propuestas sectoriales de cooperación en esta zona, y la evolución del mismo en la presente década, para lograr el análisis del comercio fronterizo binacional y la alternativa ZIF, como propuesta funcional de mejoramiento e integración sostenible en las relaciones internacionales.

\section{DESCRIPCIÓN DEL PROBLEMA}

¿De qué manera las ZIF caso Colombia y Venezuela Zona Táchira(Venezuela), Cúcuta (Colombia), en el marco de la CAN, pueden ser una estrategia de negociación que logren un proceso estructurado hacia la integración sostenible o profunda, en la actualidad? El presente artículo tiene como objetivo estudiar la negociación binacional de las zonas de integración fronteriza (ZIF), entre Colombia y Venezuela, en el marco de la cooperación, desde la teoría de la integración del funcionalismo (cooperación), y la integración sostenible, estructurando un punto de vista complementario, y descriptivo, que puede apoyar la indagación y los estudios recientes sobre estos temas, y aportar sobre este proceso. En la demostración me valdré de la recolección documental, y de las teorías; igualmente, de la indagación, de documentación primaria sobre la estrategia binacional de la ZIF Colombia y Venezuela, incluyendo un estudio de los porcentajes de flujo comercial en frontera delimitada.

\section{MARCO TEÓRICO}

Antecedentes de la integración sostenible - Conceptos.

El estudio de la integración ha tenido diverso puntos de vista y análisis, uno de ellos es la "integración sostenible", considerada como la esencia de la integración, en la que debe existir la participación de todos los factores, incluyendo los vínculos comerciales, sociales y políticos de la negociación y la cooperación, en el marco de la teoría del funcionalismo.
La palabra integración viene del vocablo latino: "integratio" que supone la adhesión, la unión de partes; la cohesión la vinculación estratégica.

En 1961, Bela Balassa publicó su libro, Teoría de la integración económica, (Consultado en www.unam.es/ documentos. "The Theory of Economic Integration", 1961. Versión castellana, "Teoría de la Integración Económica", UTEHA México 1964). En el cual establecía, una clasificación de las etapas del proceso integrador partiendo de una zona de libre cambio, hasta llegar a la integración total. Las etapas aceptadas generalmente por los teóricos son las siguientes: ${ }^{3}$

-Zona de libre cambio

-Unión aduanera

-Mercado común

-Unión económica

-Unión total

Estas características mezclan el desarrollo de la economía internacional y el proceso de negociación internacional, que abarca un proceso sistémico de organizaciones gubernamentales y empresas multinacionales, a establecer negocios y reglas de operacionalidad hacia la integración real profunda o sostenible.

La integración sostenible abarca un proceso estructurado de negociación en el que se establece la complementariedad de los procesos, y se cumplen las etapas formuladas por Balassa. Se trata entonces de explorar el concepto de sostenibilidad de la integración y sustentar porqué me baso en esta teoría de la integración actual.

La cooperación es fundamental en el desarrollo de la estrategia de sostenibilidad y de fortalecer los procesos de integración. la teoría especifica de la integración muestra además que el funcionalismo como teoría de la integración es un factor muy importante en especial en la nueva economía mundial, de comercio y de vinculaciones directas y dinámicas, por su agilidad y movilidad.

"El funcionalismo propuso la importancia de los enclaves de cooperación internacional, funcionalmente específicos y/o regionalmente concentrados, usual-

3 “Teoría de la Integración” 1969.Balassa Bella Editorial Uthea, México En www.unam.es/documentos. Consultado biblioteca virtual, 3 de marzo 2008. La integración es un esquema de pasos fundamentales para el desarrollo y establecimiento de un proceso conjunto de cohesión y sinergia de las estrategias comunes de los Estados participantes, establece igualmente una estrategia conjunta y de cooperación donde se asignan bajo parámetros y marcos en acuerdos las políticas comunes y de ajuste individual para poder acceder a un proceso de cooperación 
mente de carácter técnico en asuntos que inicialmente no involucran elementos políticos importantes para ninguno de los países participantes.

El funcionalismo propone que la integración surge y se mantiene gracias al papel de los técnicos cuya función es la de diseñar modelos en cada uno de los diferentes aspectos de interacción internacional, permitiendo la integración bajo premisas de cooperación en temas exclusivamente técnicos ${ }^{4}$.

El proceso funcional fue la herramienta de soporte que la Unión Europea (UE), tomo para su construcción y estructuración hacia el modelo actual, es importante considerar que la cooperación es un proceso vinculante donde los países que optan por negociar recíprocamente, lo realizan en términos de cooperación económica y preservando el respeto por la soberanía nacional $^{5}$.

La cooperación implica ceder soberanía y en objetividad, el comercio, y la movilidad de factores, sobre los conceptos de desarrollo hacia adentro, se trata entonces de repensar la integración y de enfocar su análisis desde el punto de vista de la cooperación, de realizar como estrategia común, opciones de vinculación no solo comercial, sino que involucren igualmente a la sociedad civil, estableciendo una ramificación ampliada desde la tecnocracia hasta todos los sectores locales y regionales, tal como lo propone Mitrany (Mitrany, David. The functional theory of politics. New York: St. Martin's, 1976); o sea, establecer cambios de abajo hacia arriba, realizando o formulando un esquema de bola de nieve, donde las iniciativas locales de las zonas pequeñas, trascienda en entidades sólidas, que puedan estar por encima de los Estados, ser autónomas, y tener el engranaje suficiente para movilizar la estructura de los Estados, de manera supranacional y eficiente ${ }^{6}$.

\subsection{LA ESTRATEGIA SUPRANACIONAL. DE- FINICIÓN Y SU PAPEL EN AMÉRICA LATINA. CASO CAN.}

La supranacionalidad ${ }^{7}$ implica establecer nuevas formas de funcionalismo, donde las instituciones regulen, de manera general todos los procesos regionales. En ese sentido, es necesario que exista supranacionalidad, con el fin de ampliar las estrategias negociadoras de la subregión en términos comunitarios y regionales; América Latina se ha caracterizado por procesos lentos y problemas estructurales que han establecido procesos de "estanca- integración", puesto que este proceso no ha tenido la suficiente fuerza para generalizarse en la región.

Es importante establecer que este modelo ha sido muy importante para los países de la CAN, como organización supranacional, en busca de una estructura sostenible posible en beneficio del crecimiento económico. En ese orden de ideas la UE se consolida como modelo supranacional, el cual ha sido adoptado por las regiones del mundo con el fin de establecer un modelo similar que se adapte a una entidad ubicada por encima de los Estados con autonomía y liderazgo, y cuyo derecho prima sobre el de los Estados integrantes, de este tipo de cooperación.

La supranacionalidad implica el establecimiento de estas entidades, que regulen todas las propuestas de manera sistemática y aplicada a cada sector, y a cada organización de los países cooperantes; igualmente dicha entidad implica autonomía y el establecimiento de instituciones encargadas de asuntos específicos. Es importante establecer que la UE ha llevado muchos años en la construcción de este proceso comunitario a partir de la voluntad política y la de los pueblos en la cesión de soberanía, y en un mayor compromiso de las instituciones comunitarias y en sus políticas de ajuste, las cuales no solo son características de libre mercado sino que van mucho más allá, estableciendo modelos adaptables a nuestras economías y abriendo espacios de integración y de crecimiento.

\footnotetext{
4 Luisa Fernanda Santamaría Revista No 37. "El desarrollo humano sostenible en el marco de la integración americana”. Tema: DOCUMENTOS OCASIONALES No. 44.Enero - Marzo de 1997.Páginas 37-61. Citando a Tokatlian, Juan. "Componentes Políticos de la Integración”, en Jaime Acosta Puertas (comp.). Integración, Desarrollo Económico y Competitividad. Santafé de Bogotá: Centro de Estudios Regionales del Tercer Mundo, Creset, 1994: 54.

5 Kaplan Marcos "Soberanía estatal-nacional". En Problemas actuales del Derecho Constitucional. Estudios de homenaje a Jorge Carpizo, UNAM, México, 1994c. La soberanía implica ceder parte de su Estado a negociaciones, y a una vinculación estrecha con el otro país, se puede vulnerar o se puede respetar según el criterio y posición que tenga el país de negociar con la firmeza de mantener su soberanía regional, y enmarcando estrategias de cambio en especial en este mundo cada vez más globalizado. En este sentido la voluntad política y la estructuración racional de un sistema de negociación más definido supone estrategias de orden sistémico, inmerso en el marco del sistema internacional y enfocado a la estrategia de cooperación, dinámica y estructurada bajo los principios formales, de tal forma que se establezcan criterios conjuntos y de ley que regulen la negociación y la hagan más formal. (Autora).

6 El establecimiento de entidades que estén por encima de los Estados desde lo local a lo regional, implica la cesión de soberanía, pero implica además que esta entidad pueda ejercer una dinámica supra estatal que beneficie de manera categórica al comercio y que sea dinamizadora de la diplomacia orientada a la cooperación y al funcionalismo, como premisa de vecindad y estrategias para la integración sostenida.

7 Entendida como el proceso que se encuentra funcional de instituciones por encima de los estados, donde prima la entidad que los mismos estados pues esta se orienta en beneficio de la comunidad.
} 
La Unión Europea lleva años de construcción y de adaptación de un proceso de cooperación donde la estructura se determinó con base en la estrategia funcionalista, en la que prima la tecnocracia y la construcción en cooperación antes que la confrontación. Estableciendo instituciones que aporten estrategias de cooperación y de negociación dedicadas a una rama dentro del proceso mismo de integración, estas instituciones interactúan de manera directa con los Estados, sin olvidar la supranacionalidad y como en ella, las instituciones comunitarias creadas se encuentran por encima de los Estados.

\subsubsection{CAN (Comunidad Andina de Nacio- nes)}

Para el análisis de la CAN es necesario visualizar nuevamente el derecho comunitario estructurado desde la UE; este paradigma completo se tomó del viejo continente y se adapto en los países de la CAN (Comunidad Andina de Naciones). "La CAN Comunidad Andina de Naciones es una organización subregional con personalidad jurídica internacional. Formado por Bolivia, Ecuador, Perú y Venezuela y por los órganos e instituciones del Sistema Andino de Integración (SAI). Sus antecedentes se remontan a 1969 cuando se firmó el Acuerdo de Cartagena, también conocido como Pacto Andino (PAC)" 8 .

"Este proceso es muy largo si no existe la voluntad de los Estados por desarrollarlos, sin dejar permear estas instituciones por los asuntos coyunturales y fortaleciéndolas por medio de una estrategia supranacional que verifique el ejercicio de sus funciones de las instituciones bajo la dirección de un acuerdo que vincule y no excluya en momentos de cambio" 9 .

En ese sentido, América Latina ha llevado décadas de ajustes estructurales enfocados al crecimiento endógeno y ha descartado, o mejor dilatado, el proceso integracionista, estancándose cada vez más, y como lo denominé, estableciendo un proceso de "estanca-integración".

Con esto, la subregión inició un proceso de cooperación comercial y de búsqueda de cooperación profun- da que implica armonizar, en aras de la integración total la voluntad de los países, incrementando el comercio y verificando continuamente la ampliación del mercado.

"La CAN ha llevado a cabo una integración comercial caracterizada por: zonas de libre comercio, arancel externo común, normas de origen, competencia, normas técnicas, normas sanitarias, instrumentos aduaneros, franjas de precios, sector automotor y liberalización del comercio de servicios; todos los países tienen una política exterior común. Ha realizado grandes esfuerzos para conseguir una integración física y fronteriza en materia de transporte, infraestructura, desarrollo fronterizo y telecomunicaciones, integración cultural educativa y social ${ }^{10}$.

Todos estos objetivos se han dilatado enormemente, ya sea por los problemas internos o por la no concreción del desarrollo mismo de la integración, incluyendo los problemas de tipo coyuntural y de política exterior tan vulnerables para la región latinoamericana; sus diferencias ideológicas, y sus estrategias endógenas de solución de controversias han limitado el acercamiento negociador en principios de ceder y optar por ganar, ganar en todas las partes.

Igualmente el GRAN (Grupo Andino, ahora Comunidad Andina), tiene una serie de instituciones de orden comunitario que no poseen la fuerza necesaria para estar por encima de los Estados como debe ser, sino que coexisten con las políticas coyunturales de los Estados, debilitando la supranacionalidad por todos estos problemas, los cuales han retrasado de manera continua el mismo proceso de cooperación, generando un proceso permanente de estanca-integración, de este modelo negociador.

Con la salida de Venezuela en 2006 se abre nuevamente el campo de estudio acerca de la eficacia de los modelos de integración en la subregión, y se visualiza con mayor fuerza, que estos esfuerzos han tenido eco local. Esto es muy importante en la medida en que lo pequeño puede redundar en asuntos de cooperación más fuertes y por lo tanto, más estructurados.

La CAN en su conjunto, como iniciativa subregional, ha avanzado en temas de complementación técnica, desarrollando acuerdos regionales en un proceso or-

8 www.comunidadandina.org. página Oficial. Con muchas reuniones cumbres y con cambios en su estructura, hacia una estrategia comunitaria, dada en 1996 con el protocolo de Trujillo, se establece una estructura dinámica, que propone mecanismos comunitarios que beneficien a todo el sistema de integración. Son casi 40 años de negociación de los países de la subregión con rasgos de cooperación funcional pero que no ha alcanzado la profundidad para convertirse en un proceso de integración sostenible.

9 Desde los comienzos de la integración en América Latina en los sesentas se llevó un modelo insostenido de sustitución de importaciones que relegó estos procesos como la ALALC y la ALADI en los ochenta, década en la cual el crecimiento fue negativo y los países de la región se concentraban en problemas de hiperinflación; y de crisis interna en los noventa. Ahora han estado más centrados en la internacionalización, pero los procesos han sido muy lentos y sin resultados concretos. Los acuerdos realizados en estas décadas son importantes, pero no han tenido la fuerza necesaria de un proceso real de cooperación funcional ni la tan anhelada integración sostenible. (Autora)

10 Página Oficial Comunidad Andina de Naciones En www.comunidadandina.org

Ha sido un proceso largo y dilatorio de los procesos con casi cuarenta años de negociaciones y adaptaciones a la estructura suprananacional, incorporando buenas alternativas no concretas en el desarrollo de la agenda internacional de la subregión. 
ganizado que se ha dilatado en su proceso mismo de negociación hacia la integración sostenible y ha avanzado únicamente en acuerdos de complementación binacional, restringiendo la implementación local, y estableciendo una ausencia en el cumplimiento de las políticas comunes definidas.

\subsubsection{Argumento central de las ZIF.}

Existe un análisis de la integración que se ha convertido en un proceso interesante: las zonas de integración fronterizas. En el siguiente capítulo me dedicaré al estudio de estas, enfocado directamente a ver, desde lo local, estrategias que pueden adaptarse en el desarrollo de la cooperación a la comunidad, y a estudiar cómo se puede plantear, con base en este esquema, una propuesta de negociación tangible y con resultados.

Es importante afirmar que la CAN se ha preocupado por las ZIF y que existen propuestas de crecimiento. Mi estudio, en adelante, va a manejar el término "glocalización" que entendemos como: “‥una palabra creada que une la globalización y la localización. Con este concepto se intenta entender el actual proceso de transformación como un engarce entre la dinámica local y global: lo local gana en significado porque debe participar en un sin número de lugares en la competencia global por los recursos. Estas dinámicas disminuyen las posibilidades de organización de las personas, que deben aceptarlo" 11 .

Este estudio se limitará a la CAN caso Colombia-Venezuela, estudiando la cooperación existente, el flujo comercial del sector más importante de la frontera y de la política exterior binacional actual ( Táchira- Norte de Santander) incluyendo datos y flujos de transacción de manera tal, que estudie los datos del comercio con la salida de Venezuela y el tiempo de la crisis diplomática, estableciendo temas de estudio entre ellos verificar como las ZIF son un proceso de funcionalidad local, que puede generar crecimiento regional y una alternativa en los procesos de dinámica de la integración, que se tienen que fortalecer y que son un punto de partida para una estrategia sostenible de integración.

\subsection{ZONA DE INTEGRACIÓN FRONTERIZA. COLOMBIA- VENEZUELA EN LA CAN}

Cuando hablamos de integración en América del Sur es necesario remitirnos al análisis y al estudio de la geopolítica de la integración y al análisis de las fronteras, en especial, en el caso de la CAN (Comunidad Andina de Naciones), desde su iniciativa y la ZIF entre Colombia y Venezuela, cada vez más dinámica y necesaria.

En la actualidad la CAN, ha hecho grandes esfuerzos por establecer estrategias geopolíticas en su forma de negociación, como la inclusión de Chile, como país asociado, pues hasta hace poco se empezó a tener en cuenta realmente la geografía de los Estados. El incremento del comercio en la zona de la frontera, llevó a la CAN a establecer políticas e instrumentos como la decisión 501 de 2001 que dice: "Se entiende por Zona de Integración Fronteriza (ZIF) los ámbitos territoriales fronterizos, adyacente de países miembros de la Comunidad Andina, para los que se adaptarán políticas y ejecutarán planes, programas, y proyectos para impulsar el desarrollo sostenible y la integración fronteriza de manera conjunta, compartida, coordinada y orientada a obtener beneficios mutuos, en correspondencia con las características de cada uno de ellos"( decisión 501 de 2001 CAN).

En este sentido la CAN ha visualizado en esta Decisión la importancia de lo local, del espacio subregional más pequeño en la búsqueda de la tan anhelada integración sostenible, las ZIF tiene los siguientes criterios:

- "En la dimensión del desarrollo social. Estimular y promover acciones orientadas a la satisfacción de las necesidades básicas de los pobladores de las zonas fronterizas.

-En la dimensión de desarrollo económico: Fomentar el crecimiento, modernización y diversificación de la base productiva de las zonas fronterizas, aprovechando las posibilidades que habilitan los mecanismos de la integración y las ventajas de la ubicación de dichas zonas respecto de los mercados subregional, regional e internacional.

11 Andreas Novy. Profesor del Departamento para el Desarrollo Urbano y Regional de la Universidad de Economía de Viena. "Economía Política Internacional". En: <http://www.lateinamerika-studien.at/content/wirtschaft/ipoesp/ipoesp-2149.htm.> Consultado 15 de abril de 2008. Igualmente, según Alvin Toffler en su obra La tercera ola, una característica social es que los pueblos, en apariencia más se abocan a lo local, pero en realidad están más interesados en lo internacional. Es decir se 'glocalizan', dan mayor importancia a lo local sobre lo regional, como desarrollo especifico de las regiones y del continente. (Ver CAN, Página Oficial- Op. Cit. 2005) 
-En la dimensión de la sostenibilidad ambiental. Procurar que el desarrollo social y económico mejore la calidad de vida de la población, considerando las limitaciones del medio ambiente y potenciando sus ventajas.

-En la dimensión institucional: Promover la participación activa de las instituciones públicas y privadas de las ZIF en los procesos de planificación, seguimiento, evaluación de los planes, programas y proyectos que permitan consolidar el desarrollo de esos ámbitos, buscando compartir obligaciones y responsabilidades.

-En la dimensión de la integración: promover en las ZIF el libre tránsito de personas, vehículos, mercancías y servicios así como armonizar y simplificar los procedimientos migratorios aduaneros y Fito-200 sanitario $^{12 " .}$

Esta situación denota la importancia galopante del comercio en las zonas de frontera, y de la necesidad de establecer políticas puntuales de cooperación regional fronteriza, que verifique a los países relacionados, dándoles una visión más local de los proyectos de negociación y por lo tanto más manejables.

En la decisión 502 la CAN establece, crear y poner en marcha los Centros Binacionales de Atención en Frontera (CEBAF); con la decisión 503 la CAN establece la permisión de ser admitidos en los países miembros en calidad de turistas, con el documento de identidad del respectivo país, sin necesidad de la visa consular y finalmente, la decisión 504 crea el pasaporte andino el cual no ha entrado en vigencia. Estas iniciativas permiten establecer mejoras en la formación regional, disminuye asimetrías, y amplía la visión geoestratégica de vecindad establecida como interacción natural.

"Las zonas fronterizas han surgido en virtud de procesos históricos previos, simultáneos o posteriores, a la fijación de límites territoriales entre las naciones aunque la definición de limites internacionales trató inicialmente de separar los espacios y las poblaciones de frontera; en muchos casos la interacción espontánea entre unas y otras continuó dando así lugar a una permanente de construcción y reconstrucción geográfica y humana. Es muy importante tener en cuenta que las ZIF son parte de una iniciativa de glocaliza- ción, de darle mayor importancia a lo local que a lo global. Ver que la estrategia comunitaria de cooperación, puede fortalecerse, por medio de las zonas de frontera, no solo haciendo un incremento comercial sino estructurando políticas conjuntas técnicas o tecnócratas (funcionalismo), con el fin de establecer un objetivo común, darle un nuevo aire a la integración y buscar la participación de la sociedad civil en busca de la integración sostenible y profunda. En la medida que se fortalezcan los países de manera conjunta, se puede pensar en el establecimiento de negociaciones globales, en este sentido considero importante que la CAN, no solo tome como paradigma la UE, sino que la adaptación a esta tome estrategias que se adapten a nuestra diversidad cultural, y comercial, a nuestro nivel socioeconómico, políticas que se adapten a nuestra subregión y cuya meta comunitaria sea la integración, que considero es una estrategia de crecimiento y mejoramiento de un proceso continuado de Estanca- integración y puede ser una salida para apartarse de este proceso negativo.

Según la CAN existen "criterios para su identificación y delimitación:

-Que sean áreas de frontera donde las condiciones jurídicas, administrativas y funcionales que se promuevan sirvan para dinamizar la capacidad productiva y comercial y la riqueza cultural de la población.

-Que comprendan, en ambos países, ciudades actualmente o potencialmente dinamizadoras del desarrollo, así como ejes de articulación vial existentes o cuya construcción esté prevista en el corto plazo;

-Que incorporen, en ambos países, áreas económica y socialmente deprimidas

-Que propicien la articulación de zonas fronterizas con alto potencial de recursos, que en la actualidad no formen parte de la frontera activa;

-Que coadyuven al desarrollo de cuencas hidrográficas binacionales en las que se localicen proyectos y actividades de interés compartido" 13 .

La primera estrategia para negociar en una zona de

12 Portal Oficial Comunidad Andina de Naciones (CAN). En http://www.comunidadandina.org/exterior/can_ue.htm. Consultado febrero 19 de 2008.Es importante establecer que la estrategia de complementación en las dimensiones de la negociación, pueden profundizar las propuestas y generalizarlas, no parcialmente sino complementaria y en la búsqueda de participación de los negociadores binacionales y la sociedad civil, en aras de establecer una estructura dinámica de cooperación funcional.

13 Socorro Ramírez. "Las Zonas de integración fronteriza: Desafíos de la comunidad andina y suramericana". Revista Cátedras de Integración Fronteriza. Convenio Andrés Bello, Serie Integración Social y Fronteras 2006:54. Cabe señalar que estas propuestas son muy importantes siempre y cuando no se queden sobre el papel y donde estas zonas posean de desarrollo equilibrado y sostenido. 
integración fronteriza, es la integración natural, es necesario considerar la geografía, y las redes que interconectan a los países que se disponen a mejorar su cooperación fronteriza.

Igualmente los dos países deben tener en cuenta que propondrán y estructurarán políticas que convengan en el establecimiento de cooperación común enfocado en el crecimiento y en la participación activa de las zonas marginadas. En infraestructura el fin es establecer mayor volumen en transacciones, y en posicionamiento del mercado, con las libertades fundamentales de este: libre circulación de bienes, servicios, personas y capitales.

Para esto es necesario que la estrategia no solo sea de papel, sino que las acciones encaminadas sean vigiladas por la entidad supranacional; en este sentido quiero hacer énfasis nuevamente en los procesos tan largos de establecimiento de una estrategia común en los países de la CAN; es imprescindible, implementar políticas que sean conjuntas y que no resulten como un juego de suma cero.

En este orden de ideas la política exterior pasa a primer plano en la medida en que los gobiernos de los dos países se deben preocupar por el establecimiento normativo de las ZIF, y encontrar siempre estrategias de cooperación conjunta que logre disipar la estancaintegración.

\subsection{1 ¿Qué ha ocurrido desde que la CAN estipuló las reglas?}

Es muy complejo y considero que en este momento se puede verificar cómo el proceso de integración se ha estancado por la falta de compromiso de los países, por la complejidad de cada una de sus economías; es muy contradictorio, pues las reglas están ya diseñadas sobre el papel, pero las acciones se condicionan a asuntos de política exterior coyuntural y no debería ser así; debería prevalecer el derecho comunitario sobre el derecho de los países, en beneficio común como estrategia de cooperación y crecimiento continuado, e impulsar lo establecido, pues existe una buena organización, la cuestión es que pueda desarrollarse plenamente, como por ejemplo, los CEBAF:

"Zonas binacionales de atención de frontera", son el conjunto de instalaciones que se localizan en una por- ción del territorio de uno o dos países miembros de la Comunidad Andina colindantes, aledaño a un paso de frontera, en donde se presta el servicio de control integrado del flujo de personas, equipajes, mercancías y vehículos, y se brinda servicios complementarios de facilitación y de atención al usuario. Los CEBAF podrán estar ubicados íntegramente en el territorio de un país, aledaño a un paso de frontera; o a un lado y otro aledaños al paso de frontera, es decir, unas instalaciones sobre el territorio de un país, y otras sobre el del país limítrofe"14.

Estos centros están oficializados por la Decisión 502 de la CAN, "el objetivo de esta norma comunitaria es promover el establecimiento de los CEBAF en los Países Miembros de la CAN, así como aprobar un marco de normas generales sobre su desarrollo y funcionamiento, para la aplicación del control integrado en los mismos.

Se entiende por "control integrado" la verificación y supervisión de las condiciones legales de entrada y salida de personas, equipajes, mercancías y vehículos que realizan, en forma conjunta en los CEBAF, los funcionarios nacionales competentes designados por el país de salida y el de entrada" ${ }^{15}$.

En este sentido ya está enmarcado todo legalmente, y de manera comunitaria, por medio de instituciones que desarrollen el proceso común en función de la cooperación y la negociación. Para poder demostrar la necesidad de mayor cooperación y de fortalecer la ZIF, como estrategia de cooperación, y crecimiento hacia la integración profunda y sostenida limitaré mi estudio a las ZIF Colombia y Venezuela, (Táchira- Norte de Santander), estudiando su contexto y su desarrollo, en especial en su principal sector de intercambio binacional fronterizo a pesar de la salida de Venezuela en 2006, reviso datos y ratifico la necesidad de ampliar esta estrategia de negociación en beneficio de un acuerdo que ha tenido tantos tropiezos, ya sea mediante el apoyo de la CAN o con nuevos acuerdos de integración subregional.

14 Página Oficial de la Comunidad Andina de Naciones: http://www.comunidadandina.org/fronteras/cebaf.htm. consultado 18 de abril de 2008.

15 Ibídem 


\subsubsection{ZIF Colombia - Venezuela}

El caso Colombia - Venezuela en estos momentos es muy delicado debido a los nuevos conflictos de política exterior, por asuntos internos y terrorismo. Mi interés es el análisis desde la perspectiva de la integración sostenible, y el flujo comercial de intercambio entre Colombia y Venezuela, zona Táchira( Venezuela) y Cúcuta (Santander), estudiando su evolución desde 2005 hasta ahora, realizando un estudio del impacto del flujo de intercambio con la salida de Venezuela y en especial durante la crisis diplomática reciente.

Los 2.219 Kilómetros de frontera, han estado rodeados de estudios y de tropiezos a la vez, los compromisos comunitarios y los problemas de política exterior han retrasado enormemente la integración de frontera, estancando el proceso y llevándolo a nuevos escenarios, que no se habían proyectado ${ }^{16}$.

Según La Investigadora Socorro Ramírez En 2004 "Cuando universidades de frontera -Los Andes del Táchira, la Libre y La Francisco de Paula Santander de Cúcuta- con el apoyo de los gobernadores de Táchira y Norte de Santander y asesores de la CAN, y del grupo académico binacional realizaron, un estudio sobre lo municipios fronterizos para proponer una posible delimitación de la ZIF, como muestra el cuadro" ${ }^{17}$.

Este estudio se limitara a esta zona por ser un punto estratégico comercial y por establecer altos volúmenes de intercambio, adicionando que es la ZIF, de mayor adelanto en su establecimiento comunitario.( Autora).

\section{Cuadro1. Delimitación ZIF (Propuesta) ${ }^{18}$.}

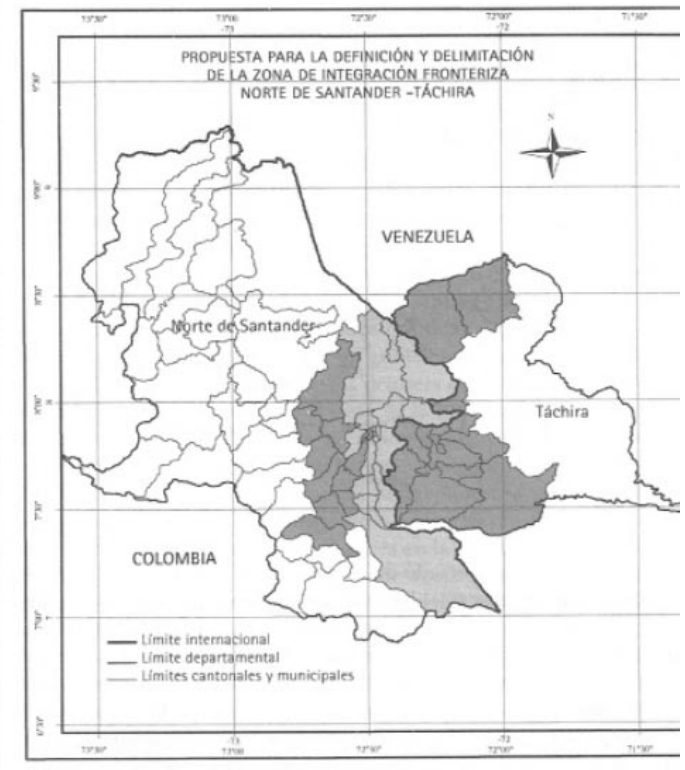

Este estudio se limitara a esta zona por ser un punto estratégico comercial y por establecer altos volúmenes de intercambio, adicionando que es la ZIF, de mayor adelanto en su establecimiento comunitario.( Autora). Lamentablemente este estudio no tuvo la importancia, ni acogida que debería tener en la delimitación de las ZIF, la coyuntura de los países, el conflicto y los asuntos de conflicto ideológico, han dilatado el análisis y ha dejado este proceso tan importante como posterior, como análisis de estudio no prioritario; considero entonces que la CAN, debe visualizar las estrategias de globalización de ver lo local, como un todo, que de esa forma las fronteras sean más dinámicas y por lo tanto los estados negociadores establecerán ventajas sobre el comercio y sobre las transacciones comerciales tanto de bienes como de servicios.

Es necesario igualmente que la CAN verifique los procesos políticos y logre conciliar el comercio reciproco y procurar mejorar la negociación con respecto a los asuntos de política exterior tan complejos y tan delicados en esta zona, fomentar la necesidad de ampliar las negociaciones comerciales y de ampliar la transferencia de tecnología y conocimiento como alternativo comunitario, y visualizar las fronteras en Colombia, como una estructura local, muy importante, para la negociación comercial, del país y su futura proyección exportadora. Cabe señalar que en la actualidad la política exterior se ha visto tensa en el sentido que se ha dilatado enormemente la negociación, las ideologías encontradas, y las posiciones contrarias, han dejado este juego de negociación como pierde- pierde, afectando especialmente al pequeño y mediano empresario.

Los gobiernos deben tomar medidas de crecimiento del comercio, ver la negociación como eje central y no como coyuntural, pues estamos hablando del futuro de nuestras empresas de intercambio y de desarrollo continuo.

El tema es muy complejo, pero considero necesario que este proceso de negociación, no se haga solo por parte de las entidades comunitarias, sino que se haga participe, directamente, la pequeña y mediana empresas y por su puesto la sociedad civil, que las propuestas trasciendas y que desde lo pequeño establezcan mecanismos globales de cambio, que sea un proceso de bola de nieve, que replique en todos los sectores, en pro de la integración sostenible y profunda.

16 Son tres zonas generales de estudio fronterizo, la zona de Maicao, la zona de Arauca y la zona de estudio Cúcuta, visto desde Colombia y su relación fronteriza. La zona general de frontera es muy importante en el intercambio comercial de los dos países, asociado esto con la premisa de la integración natural que opera bajo principios de vecindad e identidad cultural semejante (llámense idioma, costumbres, idiosincrasia). 17 Socorro Ramírez. convenio Andrés Bello. Serie 2. 70,72, Libro Publicado como serial del CAB, para América Latina.

18 Fuente: Propuesta de Definición y delimitación de la Zona de Integración fronteriza: Área Norte de Santander Colombia- Táchira Venezuela. CEFI. Universidad de Los Andes, Corporación Universidad Libre de Colombia. Seccional Cúcuta. Universidad Francisco de Paula Santander Diciembre.2004. 


\subsection{La ZIF y el comercio binacional.}

La CAN ha tenido últimamente un tratamiento especial sobre las ZIF entre Colombia y Venezuela, en especial sobre la región de norte de Santander y El Táchira.

"La razón fundamental para pensar en la creación de la ZIF en la frontera Táchira - Norte de Santander es la singularidad de la dinámica y las características de atención que los respectivos gobiernos nacionales han otorgado a este espacio fronterizo, bien sea mediante acciones de política interna como mediante la experiencia de integración subregional a través de la Comunidad Andina (CAN).El espacio limítrofe entre la República Bolivariana de Venezuela y la República de Colombia que comprende el estado Táchira y el departamento Norte de Santander, es un área geográfica caracterizada por una compenetración capaz de aminorar las diferencias entre los países y en determinados momentos ignorar las regulaciones legales de los gobiernos nacionales" 19 .

Es una ventaja de negociación importante en la medida que el flujo comercial es muy dinámico y la infraestructura ayuda a realizar un intercambio continuo, y estructurado. Dentro de la estrategia descrita anteriormente con la solidificación de las ZIF en la Decisión 501 de la CAN, se estableció igualmente la limitación de los municipios incluidos en este proyecto ${ }^{20}$.

Con esta propuesta la limitación de la propuesta ZIF establece una estrategia de globalización y funcionalidad, limitando la estrategia inicial, para establecer el desarrollo limítrofe, tal como lo dice la CAN, en su página Oficial, establecer el desarrollo fronterizo como estrategia de cooperación, y premisa de la cooperación supranacional.

Bajo estos criterios se realizo una selección de los municipios a incluir en las ZIF binacional y como diagnóstico los municipios seleccionados para implementar directamente la estrategia de las ZIF fueron:

"Municipios Cúcuta, Herrán, Ragonvalia, Puerto Santander y Villa del Rosario, de Norte de Santander, por Colombia, y Bolívar, Pedro María Ureña, Rafael Urdaneta, García de Hevia y San Cristóbal, del estado Táchira, Venezuela. La ZIF comprendería un territorio de $3.239 \mathrm{~km} 2$,correspondientes $1.555 \mathrm{Km} 2$ para el Norte de Santander y $1.684 \mathrm{~km} 2$ para el estado Táchira. La población por incluir es de 1'243.222, pertenecientes a Norte de Santander818.989 habitantes y al Táchira $424.233 " 21$.
Estableciendo estrategias de cooperación e intercambio que pueden generar estructuras crecientes, pero el contenido esencial de la cooperación y la integración han establecido un cuestionamiento esencial en la medida, que los negociadores son países que tienen unas economías similares sin contar el petróleo, en Venezuela, pero incluyéndolo se estaría hablando de una estructura no equilibrada de negociación, sin contar que los municipios no poseen la infraestructura ideal, para establecer estas zonas.

Es importante establecer que las estrategias locales deben convertirse en solidas y que en la medida que esto sea potencialmente necesario la creación de instituciones y la ramificación del funcionalismo, propongan alternativas de cooperación en la búsqueda de estrategias compartidas de crecimiento e integración sostenida, siempre y cuando estas estrategias converjan en un ejercicio de cooperación de suma común, y que los problemas estructurales no afecten a estas zonas naturalmente y geoestratégicamente formadas para la negociación, estas propuestas deben generalizar y ampliarse en las zonas de frontera y establecer mecanismos de vecindad, que trasciendan sobre todo el esquema subregional, hacia estrategias comunes que puedan estar por encima de los estados y que se fundamenten como pivote de la negociación internacional.

\subsubsection{ZIF. Colombia y Venezuela en cifras.}

Al observar preliminarmente las cifras proporcionadas por el Ministerio de comercio industria y turismo ${ }^{22}$ en relación con la evolución de la balanza comercial Colombo Venezolana durante los últimos 4 años, se puede llegar a afirmar que los flujos comerciales totalizados anualmente no guardan una relación proporcional con los sucesos políticos y de orden diplomático que se han presentado entre los dos países. Para 2004 la balanza comercial mostraba un superávit a favor de Colombia por \$596,26 millones de dólares, tal cifra se incrementó hasta llegar en 2006 a 1263.37 millones de dólares Un hecho destacable de las cifras analizadas es que la participación de Venezuela como mercado de las exportaciones colombianas empezó a disminuir una vez se produjo la salida de ese país de la Comunidad andina de naciones, en el año 2006, sin embargo no se ha producido una verdadera desconcentración ya que sigue siendo el segundo consumidor

19 Border integration zone in north of Santander Colombia - Táchira Venezuela. Difficulties for its creation and implementation. En:http://oai. saber.ula.ve/cgi-win/be_alex.exe?Acceso=T016300002677/6\&Nombrebd=saber abril 20 de 2008.

20 Ibídem

21 Ibídem

22 Página Oficial Ministerio de Industria y comercio, Colombia. En http://www.mincomercio.gov.co/eContent/Documentos/estadisticas/balanza/anual/BALP_AÑO.XLS. Consultado mayo 3 de 2008. 
de productos Colombianos después de Estados Unidos. La mayoría de exportaciones a Venezuela son de productos no tradicionales, que son los exportados por la mayoría de Micro y pequeñas empresas en Colombia, lo cual hace que estas empresas desarrollen una alta dependencia del mercado venezolano. En el primer trimestre de 2008 las ventas totales a Venezuela ascendieron a 1314 millones de dólares, un $54,4 \%$ más que en el 2007, dentro de este total US\$223,9 millones correspondieron al sector de confecciones; US\$ 204.2 millones en animales y sus productos (carne de res); 107.3 millones en productos químicos; US\$ 90.7 millones en curtiembres y sus derivados; US\$ 78.3 millones en textiles; US\$ 69.8 en alimentos, bebidas y tabaco y US\$ 66.2 millones en vehículos. ${ }^{23}$

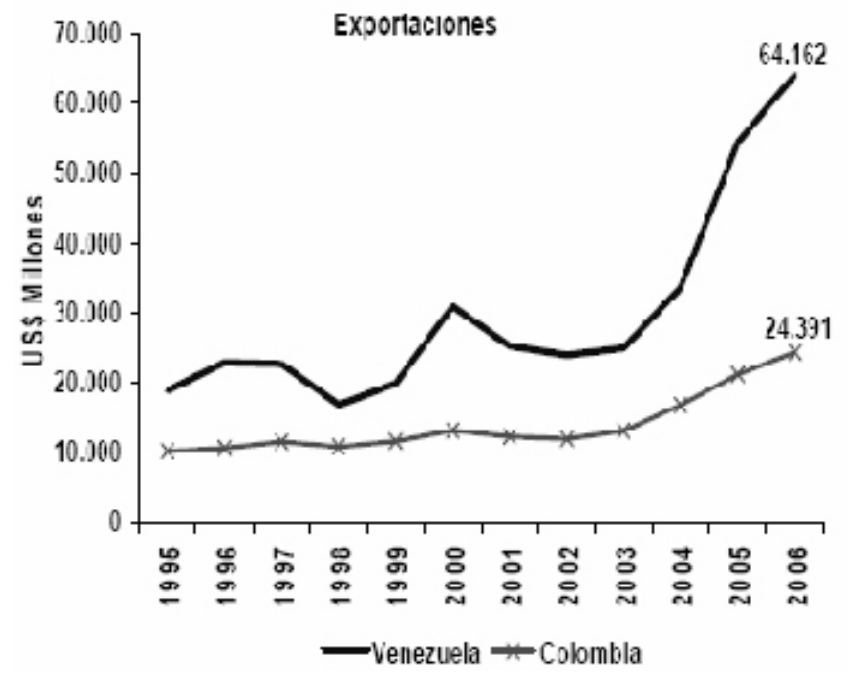

\subsubsection{Balanza comercial Colombia Vene- zuela}

\begin{tabular}{l|ll|}
\hline AÑO & SALDO BALANZA COMERCIAL VARIACIÓN \\
2005 & US\$ $\$ 34 \% 52.000$ & \\
\hline 2006 & US\$ 1.263376 .000 & $35.18 \%$ \\
2007 & US\$ 3.905974 .000 & $209.16 \%$ \\
\hline
\end{tabular}

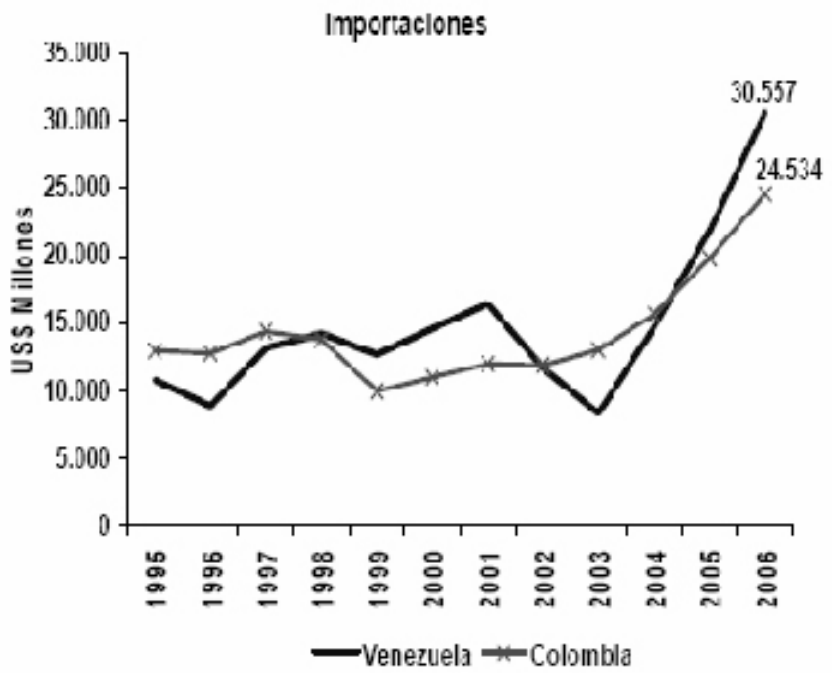

Fuente: Ministerio de comercio industria y turismo.

\subsection{La influencia de la crisis en cifras}

El 14\% de los alimentos que se venden en Venezuela son importados desde Colombia y consisten básicamente en Carne, Leche y alimentos empacados, ante la reciente tensión en el entorno bilateral Venezuela está buscando nuevos proveedores como Brasil y Argentina que le suministren los productos que actualmente importa desde Colombia, tal plan es una política a largo plazo puesta en marcha por el gobierno venezolano desde 2003. Actualmente el crecimiento de las importaciones venezolanas desde Colombia, es tan solo la mitad del crecimiento de las importaciones venezolanas desde Brasil, es tres veces menos que las de Argentina y un 30\% inferior al crecimiento de las importaciones uruguayas. $^{24}$

Dentro de las barreras interpuestas por el gobierno venezolano anteriormente enunciadas esta el otorgamiento de un certificado de origen que antes se expedía máximo en 24 horas pero ahora puede tardar días, semanas o incluso meses. Lo anterior ha generado una

23 El tiempo, 24 de Marzo de 2008, pg. 13 A, Articulo: "preocupa menor ritmo de las exportaciones"

24 La parábola del Titanic: ¿Puede hundirse la economía colombiana?, Jairo Bautista, Asesor Económico, Cámara de Representantes, en www. viva.org.co/cajavirtual/svc0101/download.php?archivo=articulo05 
disminución de las operaciones aduaneras de más de un 50\% desde marzo de este año. Los principales afectados son las pequeñas empresas de la región fronteriza que generan alrededor de 20.000 en la zona. El costo operativo por este trámite calculado por la Asociación Venezolana de Exportadores (AVEX) es de 400 millones de dólares para finales de 2008.

\subsection{Participación de Colombia en el comercio exterior de Venezuela}

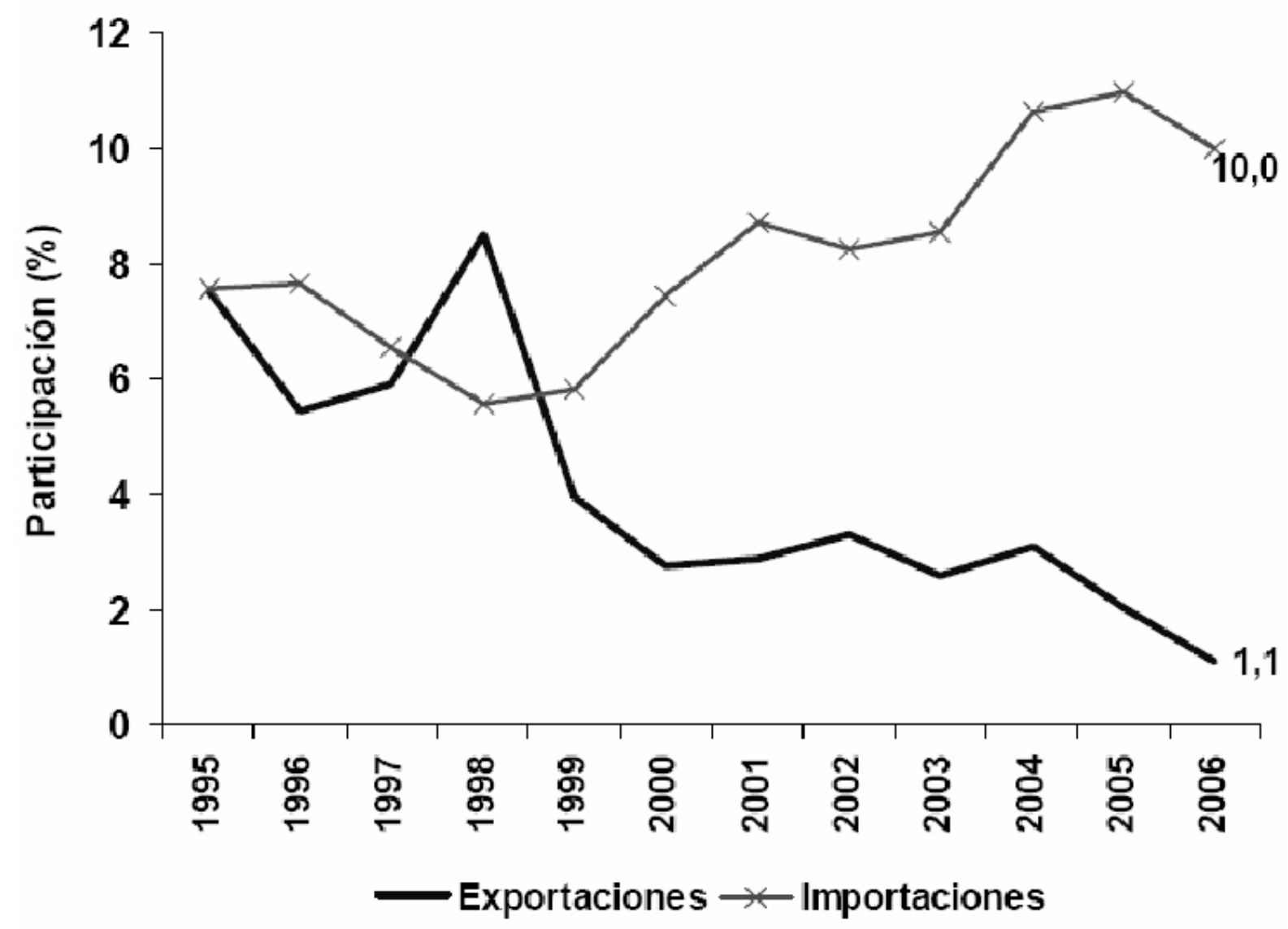

Fuente: Ministerio de comercio industria y turismo. 


\subsection{Participación De Venezuela En EI Comercio Exterior De Colombia}

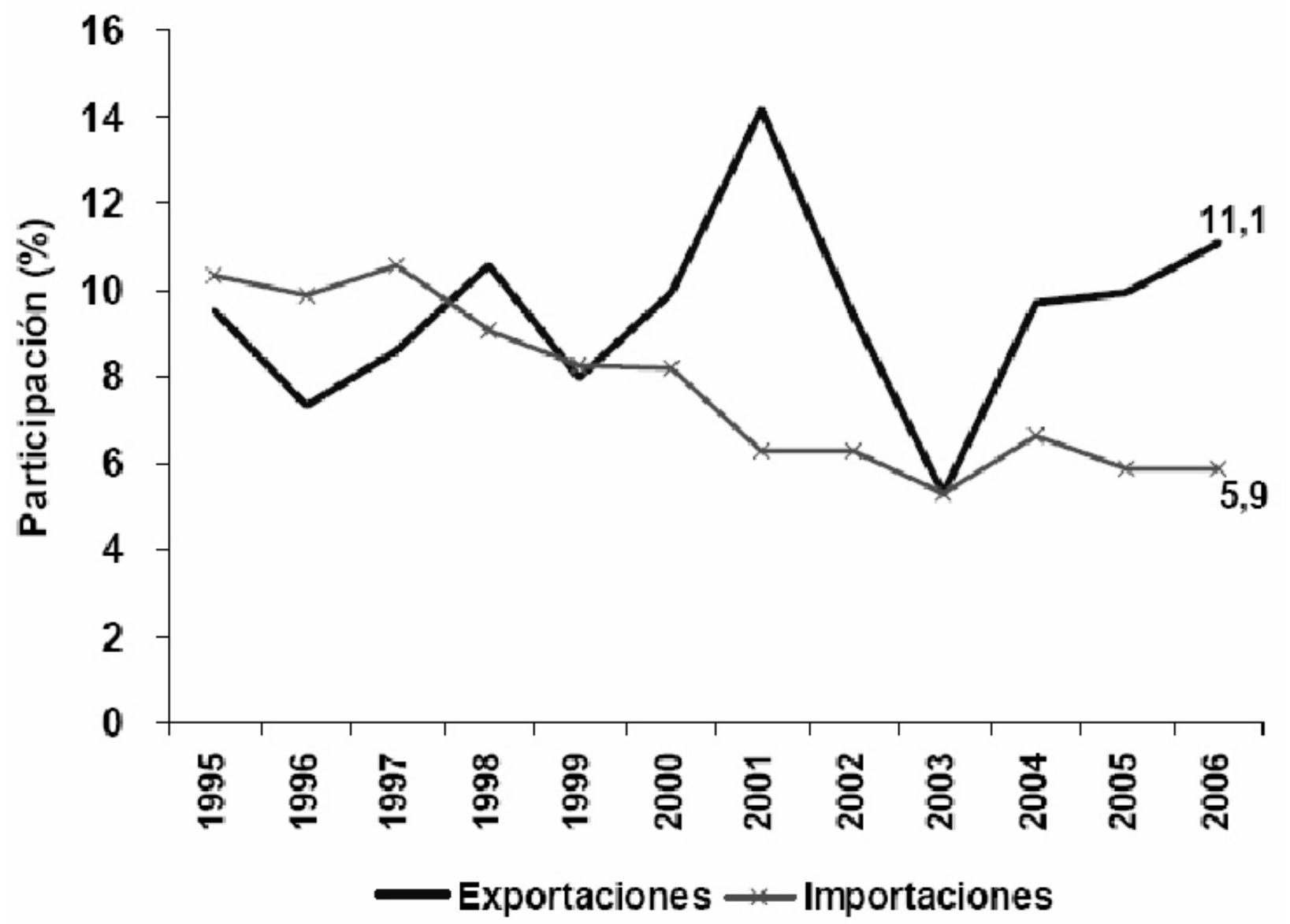

Fuente: Ministerio de comercio industria y turismo.

Un ejemplo de la interdependencia comercial entre Colombia y Venezuela es el sector automotriz, ya que ante la decisión venezolana de reducir la cuota de importación de carros producidos en Colombia se ha generado una disminución en la expectativa de exportación de alrededor del $46 \%$ dado que el año anterior se exportaron 48.000 unidades aproximadamente, mientras que para este año los cálculos mas optimistas apuntan a la exportación de solo 22.100 unidades. A su vez el volumen de fabricación disminuiría en $14 \%$ aproximadamente frente a las 181.941 unidades de 2007. Esta situación ya ha generado reducciones de personal en las principales ensambladoras como la Compañía Colombiana Automotriz y Sofasa quienes tuvieron que despedir a 440 y 374 personas en lo corrido del año respectivamente. En el caso de Colmotores se suspendió el proceso de contratación de alrededor de 450 personas. Actualmente el gremio automotriz está buscando otros mercados que ofrecen ventajas comerciales y arancelarias como Perú, México y los países centroamericanos, aunque el efecto de estas acciones no logrará compensar la reducción del mercado venezolano en el corto plazo. 
Otro sector que se ha visto afectado por las radicales medidas económicas del gobierno venezolano es el de cementos. Ante la reciente decisión de nacionalizar la industria cementera venezolana el grupo Argos de Colombia, propietario de la empresa Cemento Andino en el estado de Trujillo, tendría que negociar una indemnización con el gobierno Venezolano, de alrededor de 200 a 250 millones de dólares que cubran no solo la adquisición (84 millones de dólares) que se pagó de contado al mismo gobierno en 1997, sino también la expansión de la planta y el lucro cesante que se genere durante el proceso. Por otra parte el valor de la acción de la Compañía nacional de Chocolates en la bolsa de valores de Colombia sufrió una gran volatilidad duran-

\subsection{Exportaciones Colombianas a Venezuela}

Cifras en millones de dólares te la reciente crisis diplomática. A comienzos de 2008 el precio de la acción era de \$ 16.600 pero en el punto mas álgido de la crisis diplomática, el anuncio del cierre de la frontera por parte del presidente Chávez, el precio de la acción se redujo a \$13.740, reflejando una pérdida de $20.81 \%$ con respecto a su valor inicial en el 2008. Lo anterior se presentó dado que Venezuela representa el 10\% de las ventas de la empresa Colombiana y para este año tiene pensado invertir alrededor de $\$ 45.000$ millones de pesos en el mercado del vecino país. En ambos casos se refleja la necesidad mutua de los mercados de los dos países, por lo que se confirma la necesidad de separar y proteger el comercio binacional de la permeabilidad de los asuntos coyunturales.

\begin{tabular}{|c|c|c|c|c|}
\hline PRODUCTO & 2004 & 2005 & 2006 & 2007 \\
\hline Total & $\$ 1.627,15$ & $\$ 2.097,59$ & $52.701,73$ & $55.21[, 33$ \\
\hline Derivados del petróle 0 & $\$ 8,38$ & $\$ 10,96$ & $\$ 4,64$ & $\$ 4,39$ \\
\hline Carbón & $\$ 6,35$ & $\$ 6,11$ & $\$ 4,12$ & $\$ E_{1}, 12$ \\
\hline Alimentos & $\$ 342,51$ & $\$ 387,64$ & $\$ 530,67$ & $\$ 680,01$ \\
\hline Confecciones & $\$ 121,73$ & $\$ 170,64$ & $\$ 246,69$ & $\$ 842,19$ \\
\hline Química básica & $\$ 192,38$ & $\$ 194,24$ & 4240,99 & $\$ 337,07$ \\
\hline Maquinaría y equipo & $\$ 127,69$ & $\$ 170,40$ & (5 249,57 & $\$ 45,5,5$ \\
\hline Industría automotriz & $\$ 263,90$ & $\$ 476,47$ & 9573,26 & $598: 17$ \\
\hline Otros & $\$ 564,21$ & $\$ 673,07$ & $\$ 85179$ & $\$ 1.69 E .83$ \\
\hline
\end{tabular}

Fuente: Ministerio de comercio industria y turismo. 
Inicialmente se evidencia que la tasa de crecimiento es permanente y bastante representativa al ubicarse en un $28.91 \%$ entre 2004 y 2005 y en un $28.80 \%$ entre este año y el 2006, sin embargo tiende a crecer abruptamente entre el 2006 y 2007 al llegar a un 92.85\%. La explicación de esto radica en la desarticulación del aparato productivo interno de Venezuela a partir de la nacionalización de diferentes compañías cuyos productos no fueron remplazados en el mercado por empresas venezolanas sino que tuvieron que empezar a

\subsection{Importaciones Colombianas des- de Venezuela}

importarse, lo cual benefició a Colombia enormemente, como lo evidencian las estadísticas, ya que a excepción de los derivados del petróleo los principales productos que componen la oferta de Colombia a Venezuela han presentado un crecimiento representativo para cada uno de los periodos estudiados. Dentro de los productos mas representativos están los agrupados bajo el rubro de alimentos ya que su participación oscila entre un 17 y un $21 \%$ del total de exportaciones, así como también el sector automotriz, cuya participación esta entre un 16.21 y un $22.71 \%$.

\begin{tabular}{|l|r|r|r|r|}
\hline PRDDUCT0 & 2004 & 2005 & 2006 & 2007 \\
\hline Total & $\$ 1.081,79$ & $\$ 1,219,12$ & $\$ 1,497,61$ & $\$ 1.365,35$ \\
\hline Derivados del petróleo & $\$ 87,72$ & $\$ 79,21$ & $\$ 179,05$ & $\$ 57,65$ \\
\hline Alimentos & $\$ 40,52$ & $\$ 41,98$ & $\$ 37,57$ & $\$ 18,14$ \\
\hline Textiles & $\$ 20,25$ & $\$ 17,32$ & $\$ 18,70$ & $\$ 14,14$ \\
\hline Industria liviana & $\$ 28,02$ & $\$ 30,51$ & $\$ 36,79$ & $\$ 31,40$ \\
\hline Metalúrgica & $\$ 414,10$ & $\$ 471,47$ & $\$ 462,00$ & $\$ 494,46$ \\
\hline Química básica & $\$ 314,23$ & $\$ 378,45$ & $\$ 422,66$ & $\$ 316,88$ \\
\hline Maquinaría y equipo & $\$ 36,25$ & $\$ 45,50$ & $\$ 50,81$ & $\$ 30,54$ \\
\hline Industría automotriz & $\$ 89,48$ & $\$ 110,14$ & $\$ 244,94$ & $\$ 182,44$ \\
\hline Otros & $\$ 51,23$ & $\$ 44,54$ & $\$ 45,09$ & $\$ 212,31$ \\
\hline
\end{tabular}

Fuente: Ministerio de comercio industria y turismo.

Los dos rubros que más importa Colombia desde Venezuela están agrupados en el sector de industria básica, son productos de la industria metalúrgica y químicos. Con respecto a los primeros las importaciones se han incrementado entre un 7.02 y un $13.85 \%$ para el periodo 2004-2007, el crecimiento en la importación de productos de la industria química dentro del total de importaciones desde Venezuela también se ha incrementado sucesivamente un $11.68 \%$ entre 2004 y 2005 y un $20.43 \%$ entre 2005 y 2006 aunque para 2007 este rubro presenta un decrecimiento de $25.02 \%$.
En cuanto al crecimiento general de las importaciones se puede hablar de un incremento marginal moderado que en promedio es de $8.91 \%$. El hecho de que el crecimiento de las importaciones Colombianas desde Venezuela no se hayan incrementado de la misma forma que las exportaciones hacia ese destino es el motivo que origina el desequilibrio en la balanza comercial entre los dos países, el cual es utilizado frecuentemente como argumento por parte del gobierno venezolano para imponer restricciones al comercio como las cuotas máximas de importación que actualmente afectan 
al sector automotriz o los controles aduaneros que han incrementado los tiempos de transacción entre los dos países.

\subsubsection{Zona de integración fronteriza Norte de Santander - San Antonio del Táchira}

Para el año 2003 Norte de Santander exportó US\$ $40 ` 262.067$ de los cuales US\$13`726.609 se exportaron a Venezuela, de la misma forma en 2004 las exportaciones totales del departamento llegaron a US\$ 66 994.713, incrementándose en un 66.40\% con respecto al 2003, de la misma forma US\$ $26{ }^{\prime} 481.644$ de las exportaciones de 2004 fueron a Venezuela que, comparados a la cifra exportada a ese país en 2003 muestra un incremento de $92.92 \%$. Lo anterior permite afirmar que el crecimiento del flujo comercial binacional en la zona de integración fronteriza fue mayor en más de un 25\% al crecimiento del flujo comercial con otros mercados para el periodo estudiado. Dentro de los sectores mas representativos dentro del comercio de la zona se encuentra el de combustibles, aceites y ceras minerales que representa entre el 49 y $53 \%$ del total de productos exportados para ese periodo, así como productos de la industria cerámica y del calzado que representaron alrededor del 18\% del total de productos exportados en la zona para el periodo 2003-2004.
Para 2003 Norte de Santander importó un total de US\$ 35 '200.490 de los cuales US\$23`219.433, un 66\%, provino de Venezuela. Para 2004 las importacio-

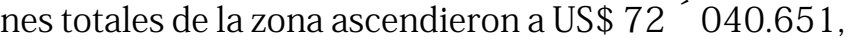
un $104.7 \%$ mas que en 2003 , mientras que las importaciones desde Venezuela en 2004 se incrementaron en un $72.9 \%$ al llegar a US\$ 52 515.333. Lo anterior evidencia una tendencia de crecimiento mayor en las importaciones frente al incremento de las exportaciones Colombianas en la región, sin embargo la tendencia no se replica en el comercio binacional con Venezuela, donde se presenta un crecimiento mayor de las exportaciones para el periodo 2003-2004. De todas formas el crecimiento marginal del flujo comercial entre un año y otro es reflejo del potencial comercial de la ZIF. Los rubros mas representativos dentro de las importaciones de la región en 2004 fueron la fundición de hierro y hacer con un $17.65 \%$ de participación sobre el total de importaciones y la maquinaria industrial que con sus insumos representan un $11 \%$ del total de importaciones.

\subsubsection{Exportaciones no Tradicionales Fob Norte De Santander 2003- 2004}

Cifras en millones de dólares.

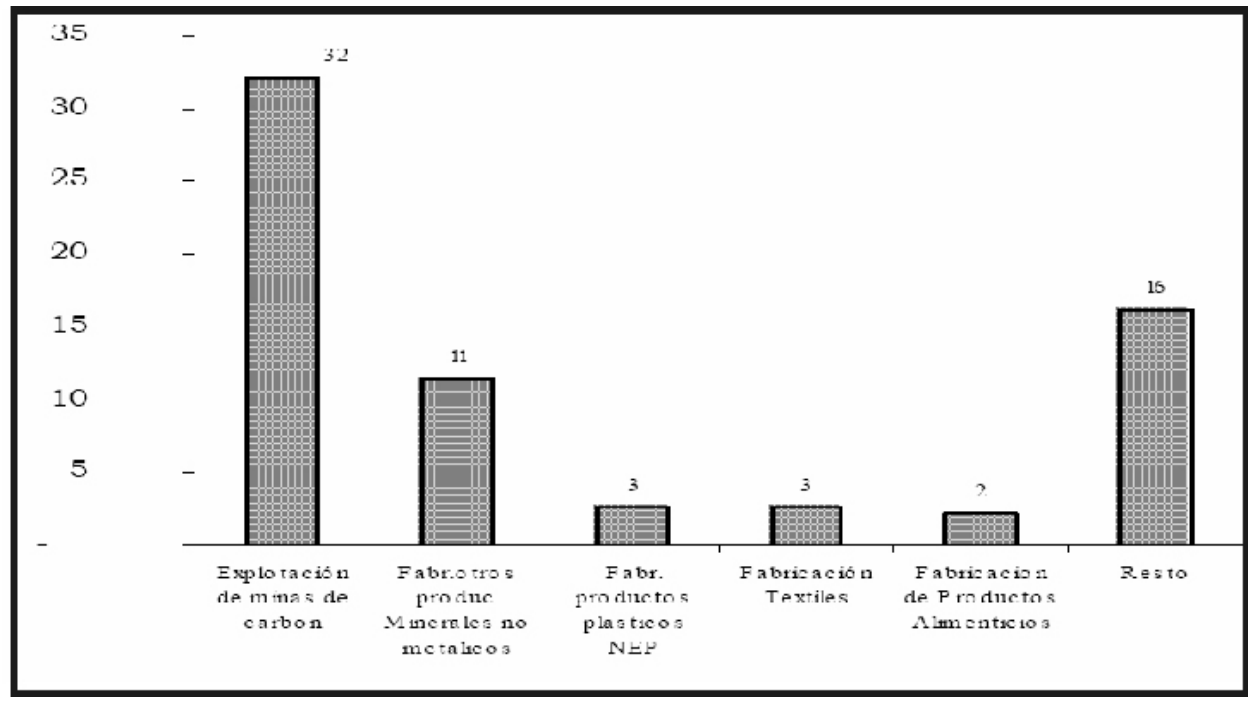

Fuente: Dane 


\subsubsection{Importaciones valor CIF Norte de Santander 2003- 2004}

Cifras en miles de dólares

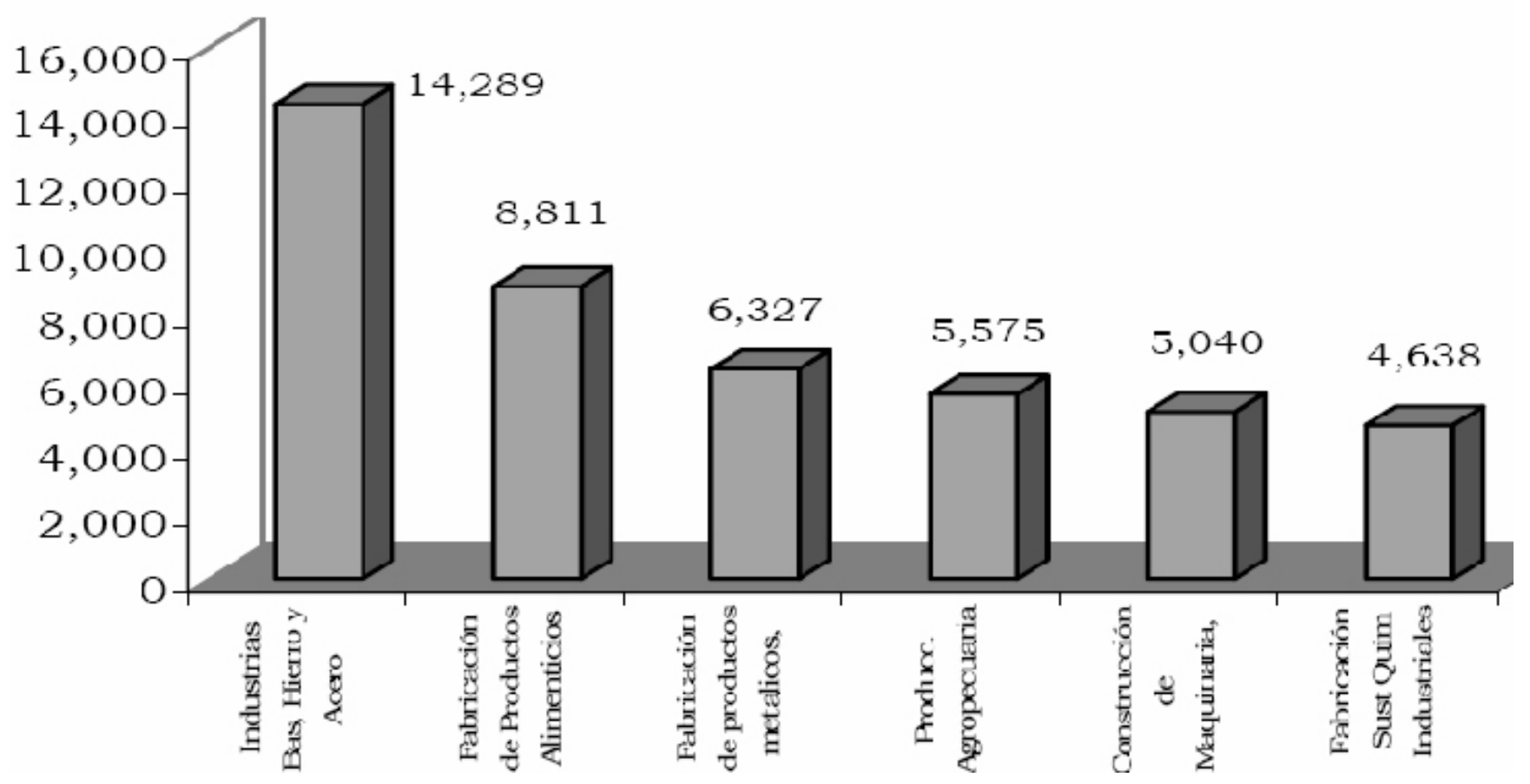

Fuente: Dane

En el primer semestre de 2005 las exportaciones de Norte de Santander llegaron a US\$ 25 603.032, en el mismo periodo de 2004 este rubro era de US\$ 10 '886.831 lo cual demuestra un incremento del $135,17 \%$. De la misma forma la participación de las exportaciones a Venezuela dentro de estos totales paso de un $66.77 \%$ (US\$ $7^{\prime} 269.452$ ) en el primer semestre de 2004 a un $81.40 \%$ (US\$20 ${ }^{\prime} 840.688$ ), lo anterior representa una variación porcentual entre ambos periodos de un $186.69 \%$. Dentro de los productos con mayor dinámica exportadora se encuentra la industria cerámica y la industria del calzado con una participación del $30.33 \%$ y del $12 \%$ respectivamente para el periodo referido.
Por su parte las importaciones muestran un incremento en la cifra total para la región entre el primer semestre del 2004 y el mismo periodo de 2005 de un 29.3\% al pasar de US\$ $33^{\prime} 005.069$ a US\$ 42 679.307, mientras que las importaciones desde Venezuela presentaron un incremento marginal entre los periodos referidos de un $16.2 \%$ al pasar de US\$24 331.049 a US\$ 28 '283.096. Sin embargo, también se presenta una especie de desconcentración de las importaciones provenientes de Venezuela ya que la participación de las mismas dentro del total pasa de $73.7 \%$ en el primer semestre de 2004 a $66.27 \%$ en el primer semestre de 2005 , aunque de todas maneras este país sigue siendo el primer proveedor de bienes y servicios en la región. 
Dentro de los principales productos que se importaron en el periodo referido esta la maquinaria e insumos industriales con una participación de $16.47 \%$ dentro del total de importaciones. En segundo plano están los derivados de la industria de fundición de hierro y acero con una participación del $12.44 \%$.

Según el DANE ${ }^{25}$, para 2006 Norte de Santander exportó a todo el mundo un total de US\$116`684.460, de los cuales un $63.6 \%$ (US\$ $744^{\prime} 350.031$ ) tuvo como destino el mercado venezolano, por su parte las importaciones de Norte de Santander ascendieron a US\$ 58 ‘391.557 de los cuales US\$ 41'849.616 (71.7\%) se realizaron desde Venezuela. Así pues se puede afirmar que la viabilidad del intercambio comercial en la zona de integración fronteriza es sustentable y hacia futuro tiende a incrementarse a medida que las empresas de ambos países encuentren oportunidades de negocio a partir de las condiciones especiales que la ZIF les ofrece.

Un ejemplo de lo anterior es el caso del régimen administrativo del sector azúcar impulsado por el gobier- no del Táchira. El sector del azúcar es primordial en la región pues genera 1600 empleos directos y 6900 indirectos para ciudadanos de ambos países, por otra parte este sector involucra a diferentes eslabones de la cadena de valor desde el cultivador, pasando por el transportador hasta el comercializador, el consorcio Colombiano CIAMSA. La fábrica de azúcar está ubicada en Ureña, Venezuela pero requiere de la producción de materia prima desde ambos lados de la frontera para generar márgenes aceptables de rentabilidad. Para facilitar el proceso de producción a los trabajadores de ambos lados de la frontera se les concede un permiso temporal de trabajo que les permite movilizarse de su residencia a su sitio de trabajo de manera legal.

Esta iniciativa cuenta con respaldo gubernamental de ambos países que se evidencia en aspectos como el plan de mejoramiento ambiental para el manejo de la quema de residuos de la cosecha de caña de azúcar y el programa de restitución de vehículos para los transportadores de caña de azúcar, que facilita condiciones de crédito para la adquisición de vehículos nuevos que sean destinados a esta labor ${ }^{26}$.

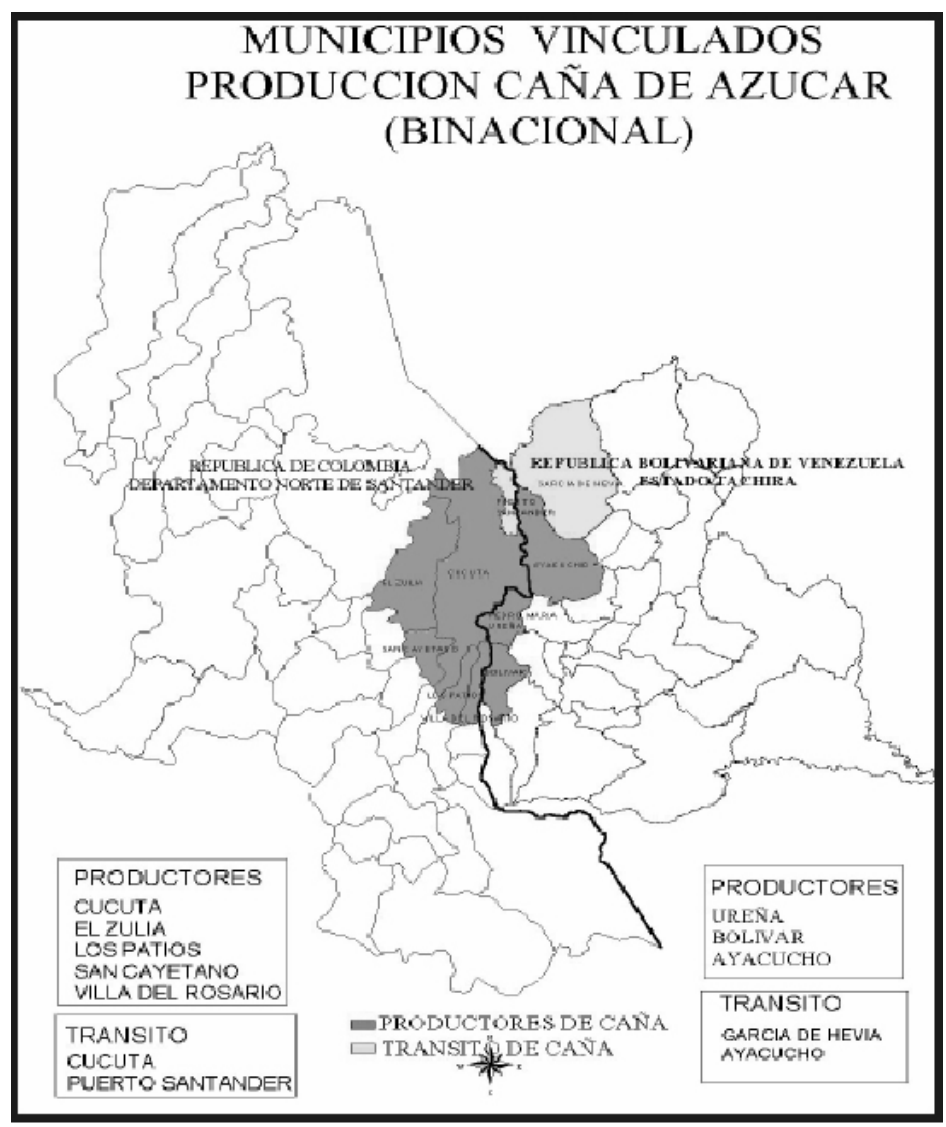

25 www.legiscomex.com, Países destino y de origen de las exportaciones e importaciones de Norte de Santander, Diciembre 12 de 2006. 26 El régimen del sector azúcar en la zona de integración fronteriza entre Colombia y Venezuela: Una nueva forma de vecindad, Francisco Javier Sánchez C. Profesor -Investigador del Centro de Estudios de Fronteras e Integración (CEFI), Universidad de Los Andes, Táchira - Venezuela 
Las cifras muestran que los países tienen una dinámica importante en estas zonas de frontera, caso especial de estudio Táchira( Venezuela) Norte de Santander ( Colombia), en ese sentido los procesos funcionales de cooperación durante la salida de Venezuela no se afecto como se esperaba, igualmente la dinámica negociadora entre los dos países ha estado centrada en el intercambio continuo y en la organización comercial binacional.

\section{CONCLUSIONES}

La estructura funcional que se demanda en las Zonas de Integración fronteriza, es vinculante en la medida que estos procesos locales y glocalizados, pueden generar una dinámica a nivel internacional, especificando que es evidente y directa la cantidad de flujo comercial de las zonas de frontera, y que esta dinámica es evidente y de integración regional, dando lugar a una estrategia de vecindad funcionalista que implica una solidez de estas zonas, que realizan de manera natural el comercio y por decirlo de alguna manera de carácter espontáneo y estableciendo una visión de entidad funcional o ramificada, que implica la especificación y ampliación del flujo comercial.

En este sentido la cooperación internacional pasa a tener una importancia enorme en estos procesos locales, y la CAN ha establecido la normatividad adecuada para el establecimiento y desarrollo de estas zonas,

La idea central es que estas propuestas locales no se queden en papel y no se pierdan las iniciativas comunitarias, por lo tanto se debe establecer la organización de instituciones que se encuentren por encima de los estados, que se encarguen de los asuntos de vecindad y frontera.

En la medida que se establezca la importancia que se le debe dar a lo local y que la organización se lleve a un acuerdo llámese CAN o la nueva UNASUR, estas estrategias redundaran en la tan anhelada posibilidad de una integración sostenida, que involucre todos los sectores y amplié la proyección integracionista a un proceso global que pueda incursionar en la interdependencia actual del mundo.

La evidencia en las cifras es contundente pese a la salida de Venezuela y a la crisis diplomática el flujo comercial disminuyó, pero no en las proporciones negativas que se esperaban, se evidencio que el flujo comercial se mantuvo y el intercambio en la zona de integración fronteriza específicamente seleccionada de Táchira(Venezuela) y Cúcuta (Colombia), se ha mantenido como zona de comercio reciproco y de una vinculación funcional potencial, que genera una gran propuesta ver lo local y partir de esta para lograr estrategias regionales y globales. 


\section{BIBUOGRAFÍA}

-Acosta Puertas, Jaime y Santamaría, Luisa Fernanda. "El desarrollo humano sostenible en el marco de la integración americana”, en: Bogotá. Documentos ocasionales, núm. 44, enero-marzo, 1997, pág.37-61.

-Balassa, Bela. Teoría de la Integración Económica. México: UTHEA, 1964.

-Balassa, Bela. Trade Creation and Trade Diversion in the European Common Market. UTHEA, 1967.

- Bisceglia, Nicolás Emiliano. (2008). "Los procesos de integración y cooperación: hacia un modelo posible" [en línea], disponible en: Foro para la proyección política de la unidad sudamericana,<http://www.unionsudamericana.net/castellano/notas/opi_003.html>, consultado: 13 de marzo de 2008

-Bustamante de Pernía, A. M. y Caraballo, L.Javier. (2008). "Zonas de Integración Fronteriza (ZIF) en Norte de Santander (Colombia) - Táchira (Venezuela). Dificultades para su creación e implementación" [en línea], disponible en:<http://209.85.207.104/ search?q=cache:v20aWWJbvzEJ:saber.ula.ve>, consultado: 20 de abril de 2008.

-Bautista, Jairo. (2007). "La parábola del Titanic: ¿Puede hundirse la economía colombiana?” [en línea], disponible en: Corporación Viva la Ciudadanía, <www. viva.org.co/cajavirtual/svc0101/download.php?archi vo=articulo05.>, consultado: 3 julio 2008.

- Cardona, Diego. “ ¿Tiene futuro la Comunidad Sudamericana de Naciones?”, en Nueva York: Foreign Affairs en Español, vol. 5, núm. 55,2005, pág.84-92.

-Keohane Robert. After Hegemony: Cooperation and Discord in the World Political Economy. Princeton NJ: Princeton University Press, 1984.

-Mora, Ramírez. Ángela Julieta. (2000) "Sostenibilidad de la Integración. Un punto de vista alternativo" [en línea], disponible en: Revista Expectativas, <www. utadeo.edu.co/expectativas>, consultado: 23 de mayo de 2008.

-Mora Ramírez, Angela Julieta. "El ALCA Un paradigma" en Montevideo: Revista GEOSUR Asociación latinoamericana de Estudios Geopolíticos e Internacionales, 2003, pág, 15-23.

-Mora Ramírez Angela Julieta. "La integración fronteriza Colombia- Venezuela, desde la visión de la teoría de la integración sostenible. En Montevideo (Uruguay), En Revista GEOSUR, Asociación Latinoamericana de Estudios geopolíticos e Internacionales- Uruguay. Número 337-338, mayo-junio de 2008, pág,15-31. -Mitrany, David. (1975). "The functional theory of politics" [en línea], disponible en: CEPC, <http://74.125.45.104/search?q=cache:BefjGsR-
B7RsJ:www.cepc.es/rap/Publicaciones.>, consultado: marzo de 2008.

-Novy, Andreas. (2008). "Economía Política Internacional" [en línea], disponible en: Departamento para el Desarrollo Urbano y Regional de la Universidad de Economía de Viena < http://www.lateinamerikastudien.at/content/wirtschaft/ipoesp/ipoesp-2149. htm.>, consultado: 15 de abril de 2008.

-Godard, O y Beaumais, O. "Économie, croissance et environnement De nouvelles stratégies pour de nouvelles relations Revue économique", en Paris: Perspectives et réflexions stratégiques à moyen terme, Vol. 44, Numéro Hors série: Francia,1993, pág. 143-176.

-Ramírez, Socorro. "Bogotá 2006: Ámbitos diferenciados de las Fronteras Colombiana. Las Zonas de integración Fronteriza: Desafíos de la CAN y Suramérica", en Bogotá: Revista Oficial: "Cátedra de integración" Convenio Andrés Bello, septiembre de 2006, pág. 5192.

-Rey, Germán. (2008). “Integración y re acomodamientos de las industrias culturales: Organización de Naciones Unidas, para la educación la ciencia y la cultura" [en línea], disponible en: <http://portal.unesco. org/culture/es/ev.2008.>, consultado: 13 de abril de 2008.

-Sánchez C Francisco Javier. (2008). “El régimen del sector azúcar en la zona de integración fronteriza entre Colombia y Venezuela: Una nueva forma de vecindad" [en línea], disponible en: Página Oficial cámara Colombo- Venezolana, <http://www.comvenezuela. com/>, consultado: 23 de julio de 2008.

-Página Oficial Comunidad Andina de Naciones. (2008). Decisiones CAN Comunidad Andina de Naciones: 501, 502, 503. "Con las cuáles se reglamentan y normatizan las políticas de negociación en las zonas de integración fronteriza”. Disponible en: www.comunidadandina.org. Consultada durante toda la investigación.

- Colombia, Departamento Nacional de Planeación (DNP) 2001 Documento Conpes 3155, por medio de la cuál reglamenta: "Colombia y sus fronteras: "políticas de frontera”, caracterización regional socioeconómica comparada por países y departamentos fronterizos", Adoptado en Bogotá, diciembre de 2001. En: página oficial DNP www.dnp.gov.co. Consultado 16 de agosto de 2008.

-Legiscomex. (2006). "Países destino y de origen de las exportaciones e importaciones de Norte de Santander" [en línea], disponible en: <www.legiscomex.com>, consultado: septiembre 12 de 2008. 